\title{
Design of an adiabatic air conditioning package system
}

\author{
Sachin Sunil Mothiravally and Sachidananda Hassan Krishanmurthy ${ }^{*}$ \\ School of Engineering and IT, Manipal Academy of Higher Education, Dubai, UAE
}

Received: 19 September 2021 / Accepted: 18 November 2021

\begin{abstract}
Air conditioning plays a significant role to maintain a cool atmosphere in warm conditions, However, the power consumed by the machine is higher. The commercial prevailing cooling systems are required to operate ventilation and cooling systems in buildings and in turn consumes more power. These systems apart from consuming electricity it also adds to the $\mathrm{CO}_{2}$ emissions to our environment. These energy consumption and $\mathrm{CO}_{2}$ emissions can be decreased by the assistance of energy effective frameworks to the prevailing air conditioning system. The study was conducted on a package unit of $414.2 \mathrm{~kW}$ by measuring the relative humidity, dry bulb, and wet bulb temperature to investigate the effect of indirect evaporative cooling on the systems COP. Also, the modelling of the package unit was done using Creo software and the analysis was carried out using ANSYS considering the flow and thermal analysis for different components of the package units. From this analysis it can be observed that by implementing the adiabatic cooling in package unit it is possible to save energy consumption. From the results it can be concluded that energy efficiency was more and the return on investment is high. Also, coefficient of performance of this machine is high and consumes less electricity and the expected energy savings is $20 \%$.
\end{abstract}

Keywords: Package unit / energy consumption / humidifying process / evaporative cooling

\section{Introduction}

A package unit is an HVAC (Heating ventilation and air conditioning unit) which has all the air conditioning components in a single housing. In these package unit systems, the compressor, cooling coil, air handling unit and air filter are all contained within the same enclosure. The capacity of the package unit normally ranges from 5 to 110 tons. This type of package unit is perfectly suitable for warehouses, huge halls, schools, mosques, and other heavyduty applications. As the capacity of package unit increases, the load consumption of the package unit increases. Therefore, implementing an adiabatic cooling system in an aging or working package unit would result in drop of energy consumption of the unit without affecting the original cooling capacity. Based on the package unit in case of HVAC system, literature review has been performed and presented as follows.

Porumb et al. [1] have studied and reviewed indirect evaporative cooling technology to know the importance of these systems in future technologies due to its low energy consumption and high efficiency and wide range of applications. They reviewed the theory and working principles of these systems. They concluded that these

\footnotetext{
* e-mail: sachidananda@manipaldubai.com
}

systems are environmentally friendly and less global warming impact and are suitable for different applications in commercial, industrial as well as residential centers. Basediya et al. [2] has studied the evaporative cooling system for the storage of vegetables. They studied the use of evaporative cooling systems in horticultural produce in tropical and subtropical countries because of efficient and economical cooling. They concluded that evaporative cooling can be used for preservation of vegetables and fruits for short term after harvest, also can be used to increase the relative humidity which is essential for freshness of vegetables and fruits. Jafari et al. [3] has studied the evaporative cooling system for engine thermal management in case of automotive applications. They studied evaporative cooling system to identify the short comings and the questions arising to use this technology in automobile applications. They concluded that the challenges such as modes of heat transfer, physics of vapor formation during vibrations in case of automobiles, established heat transfer and heat flux predictive capability needs to be accounted for use of these systems in automobile applications. Sibanda et al. [4] have studied the indirect air cooling along with the evaporative cooling in tomato fruit for temporary storage under the conditions of hot and humidity. They measured the temperature and RH (Using psychometric unit) hourly during a period of 28 days. They concluded that storage temperature was lower whereas 
the RH was higher as compared to the ambient condition. They also concluded that indirect air cooling along with evaporative cooling can provide optimum storage conditions and can be considered as low-cost technology for storage of fruits and vegetables in hot and humid areas. Ramzan et al. [5] energy efficiency through condensate evaporative cooling. They used honeycomb wet pad which uses evaporative cooling to decrease the temperature of the surrounding and they showed the performance efficiency using experimental method. They concluded that condensate assisted evaporative cooling has shown improvement in the cooling capacity and reduction in power consumption. Yang et al. [6] has studied the spray evaporative cooling system in case of air-cooled chilled condenser. They used a new gas-liquid two phase swirl nozzle which is characterized by high atomization quality and low power consumption by combining spray evaporative cooling system with air cooled chiller. They concluded that the power consumed by the compressor is less as well as COP (Coefficient of performance) increased due to spray evaporative cooling system. Yan et al. [7] has studied the evaporative cooling system considering the sea water and fresh water. They used sea water with different concentrations and fresh tap water for the study and developed the correlation between of heat transfer coefficient with sea and fresh water. They concluded that using sea water for evaporative cooling have significant benefits for cooling in coastal areas. Abaranji et al. [8] has studied the evaporative cooling system by considering a porous material ability for water storage medium eliminating the pump and the sump by considering different RH conditions. They measured the cooling capacity, effectiveness, and water evaporation rate to study the performance of the developed evaporative system. They concluded that porous material considering vermicompost could be used as an energy efficient to replace pad-pump-sump used in conventional evaporative cooling systems. Sawant et al. [9] has studied the evaporative cooling to study the condenser pressure to evaluate the energy efficiency performance. They developed a novel system to study evaporative cooling on the condenser side and they concluded that evaporative cooling considering honeycomb structured cellulose bonded pads can be used to enhance the performance of this system. Jain and Hindoliya [10] has studied the vapor compression refrigeration-based air conditioning commonly used in offices and commercial buildings. They evaluated analytically the energy saving potential using evaporative cooling system. They concluded that indirect evaporative cooling can be used for thermal comfort in case of offices and building with less energy savings. Raza et al. [11] has studied evaporative cooling system to study the performance in case of agricultural storage and livestock air-conditioning applications. They conducted the experimental study for climatic conditions and the data was collected ever hour and daily basis. They concluded that hybrid evaporative cooling systems can be developed for a wide range of applications. Noor et al. [12] has studied evaporative cooling systems for buildings air conditioning systems. They studied the seven AC different configurations for building considering cooling capacity, system performance, energy savings etc. They concluded that hybrid evaporative cooling is the best optimum configuration in terms of energy savings. From this literature review it is observed that most of the work was based on reducing the energy consumption, increasing the cooling capacity and effectiveness of the system. So, in this research paper an attempt has been made to study adiabatic air conditioning package system and to study energy saving if adiabatic system is included in package unit.

\section{Methodology}

The 3D design of the package unit was modelled using CREO and thermal analysis of the components have been done using ANSYS software.

\section{Designing of the package unit components}

To study the adiabatic process in package unit, the components such as nozzle, membrane, nozzle panel, fog pump, filtration system and control valve have been designed using Creo software and the details is as follows.

\subsection{Nozzle components}

The nozzle is an important component in the package unit and is essential to the misting system in reducing the temperature around the condenser coil. The nozzle selected is a small droplet size dense misting nozzle taking into consideration humidification level, fog type, fog pattern, design features and spray characteristics. Humidifying systems typically require a little amount of spray. The amount of water required to raise the humidity depends upon the ambient humidity level, the rate at which the local air is exchanged with the surrounding environment and depends upon ventilation (temperature of the room and evaporation rates) and air flow. To achieve swift humidification from a spray nozzle one needs to keep the droplet size as small as possible and to distribute the water over a wide area. This will help the small droplets evaporate into the air as quickly as possible raising the humidity level.

Misting or fog pattern spray nozzles generate fine atomization of water, which is effective at increasing humidity levels. Even at typical ambient temperatures, the little water droplets created by these nozzles can evaporate quickly, increasing the amount of water present in the air. Under most general atmospheric environmental conditions, only a relatively small amount of water is required to evaporate and effectively increase the relative humidity. For fine atomization to occur we require atomization nozzle which will produce water droplets sizes between 20 and 30 microns. The spray nozzle modelled for the analysis is as shown in Figure 1.

\subsection{Membrane panel}

BY 70M is a polyurethane alloy cell material installed in an anodized aluminum case that makes up the membrane. The membrane is placed close to the condensing unit. 

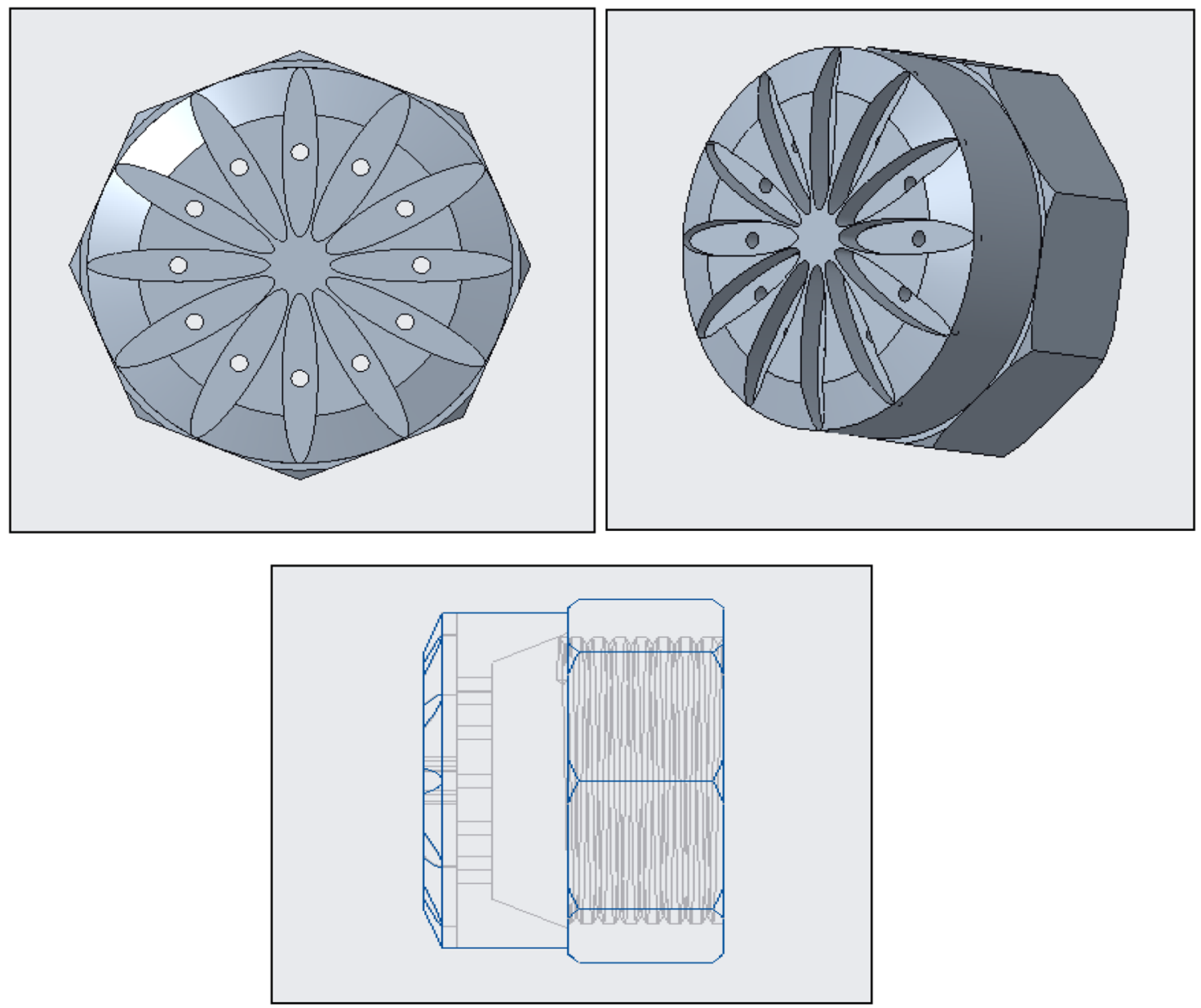

Fig. 1. Creo model of small droplet size dense mist nozzle.

Membrane is with filtering panel for condenser (coil) shield. Adiabatic membrane safeguards the condenser from direct contact with water, mist, dirt, and direct sunlight thus protecting the condenser and increasing the heat exchanging efficiency (refer Fig. 2) of the compressor. Condenser coil protection is very vital since this provides long service.

\subsection{Nozzle panel component}

The nozzle panel is made of stainless steel and aluminum alloy of the finest quality. The fine water spraying components are released through a stainless-steel nozzle routing that is inserted in a high resistance anodized aluminum housing. It was created to make installation and maintenance as simple as possible. The nozzle is fastened to the casing using fasteners to ensure a secure fit on any air conditioning unit and is as shown in Figure 3. The other components of the package unit such as fog pump, filtration system and control valve have been designed using Creo software.

\section{Results and discussion}

The analysis of the components was performed using the ANSYS software [13-15]. The nozzle has been designed considering 316 Brass material and the flow analysis has been performed. The corresponding meshing of the nozzle, the inlet and outlet boundary conditions and the flow analysis is as shown in Figure 4. From this analysis it can be understood that the streamline traces of the fine dense small droplet size can be achieved with a maximum velocity of $8.787 \mathrm{e} 001 \mathrm{~m} / \mathrm{s}$.

The analysis of the nozzle panel considering the material as highest-grade stainless steel and aluminum alloy along with the meshing, boundary conditions and analysis is as shown in Figure 5. From this analysis it is stated that the maximum velocity of the droplet in nozzle panel achieved is $1.148 \mathrm{e} 001$.

Figure 6 shows the meshing of membrane panel and the temperature applied and the corresponding steady state thermal analysis. This membrane panel is used to separate the ambient temperature and condenser coil temperature and to protect the coil from direct contact with water particles. From this analysis the maximum temperature encountered is 49.365 degree maximum centigrade which is an ambient temperature and the minimum of 35 degree centigrade in condenser coil is achieved. From the heat flux analysis, it is observed that the maximum heat flux is $0.000663 \mathrm{~W} / \mathrm{mm}^{2}$ and the minimum of $4.0865 \mathrm{e}-6 \mathrm{~W} / \mathrm{mm}^{2}$ is observed. 

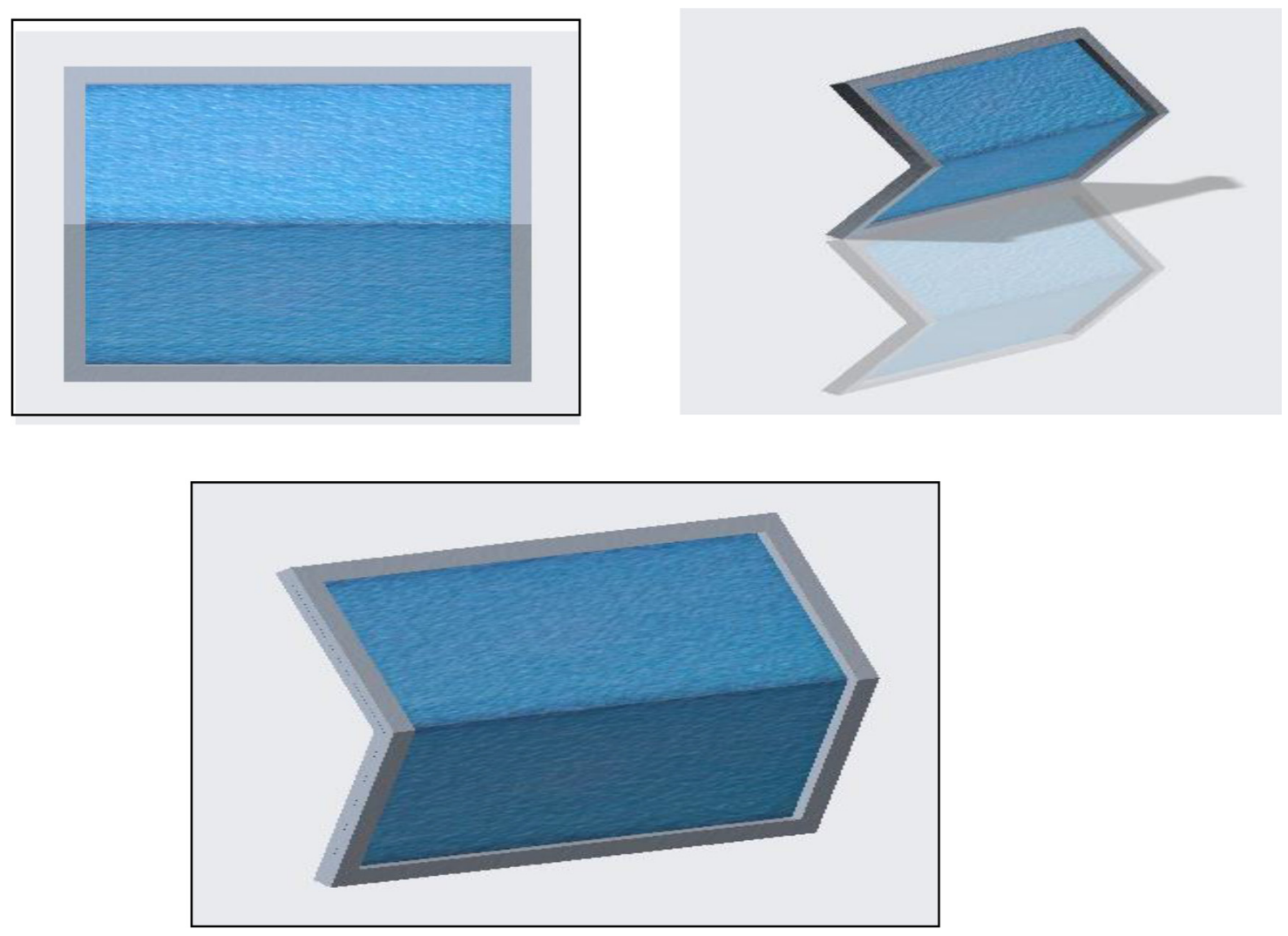

Fig. 2. Membrane panel.

\subsection{Package unit design}

PACV-D series 54125-D [16] package unit were used for the design which produces 117 tons of refrigeration and is perfect for warehouses, large halls, schools, mosques, or anywhere a heavy-duty unit with a semi-hermetic compressor is required.

\subsection{Package unit design features}

The 54125 PACV-D package is a self-contained package air conditioner that is exceptionally durable, heavy-duty, long-life, and energy efficient.

- Compressors: The PACV-D series uses reciprocating compressors that are fully accessible and semi-hermetic. An oil sight glass, suction and discharge service valves, and a crankcase heater are included. All the compressors are refrigerant gas cooled and have an oil pressure lubrication system installed. An oil screen protects the oil pump in either direction, or a valve allows for the installation of an oil pressure gauge.

- Condenser coils: To guarantee optimal heat transfer, condenser coils are made of seamless copper tubes mechanically connected to aluminum fins. Other condenser fin materials, such as Copper fins, Electro tinned Copper Fins, Copper finned coils with electro-tinned after manufacture, Precoated Aluminum fins, and Aeris Guard Coil Coating, are available for varied application requirements.
- Condenser fans: Electric motors directly drive propeller-style condenser fans with aluminum alloy blades. Motors are Totally Enclosed Air Over (TEAO) six poles with class ' $F$ ' insulation and minimum IP55 protection.

- Evaporator coils: To ensure optimal heat transfer, evaporator coils are made of seamless copper tubes mechanically connected to aluminum fins. Under water, air pressure of 300 psig $(2067 \mathrm{kPa})$ is used to test all evaporator coils for leakage. The DX evaporator coils come with seamless copper tube headers. Other condenser fin materials, such as Copper fins, Electro tinned Copper Fins, Copper finned coils with electro-tinned after manufacture, Precoated Aluminum fins, and Aeris Guard Coil Coating, are available for varied application requirements.

- Evaporator Fan Drives: are double inlet, double width centrifugal fans with forward curved impellers that ensure efficiency and silent operation. All fans are statically dynamically balanced, with adjustable pitch pulleys standard on belt-driven motors up to $11 \mathrm{~kW}$. Fixed pitch pulleys are standard on motors over $11 \mathrm{~kW}$.

- Refrigerant Circuit: The refrigerant circuit of the 54125 PACV-D series includes a sight glass, filter drier, thermostatic expansion valve, solenoid valve, shut-off valve, and a full operating charge of R-134a in each circuit as standard.

- Filter Section: Filter Sections of the 54125 PACV-D series can be configured with a variety of filter sections and filters to suit the most stringent needs. The machine includes a bag filter section that may hold 15", 21", or 30" 

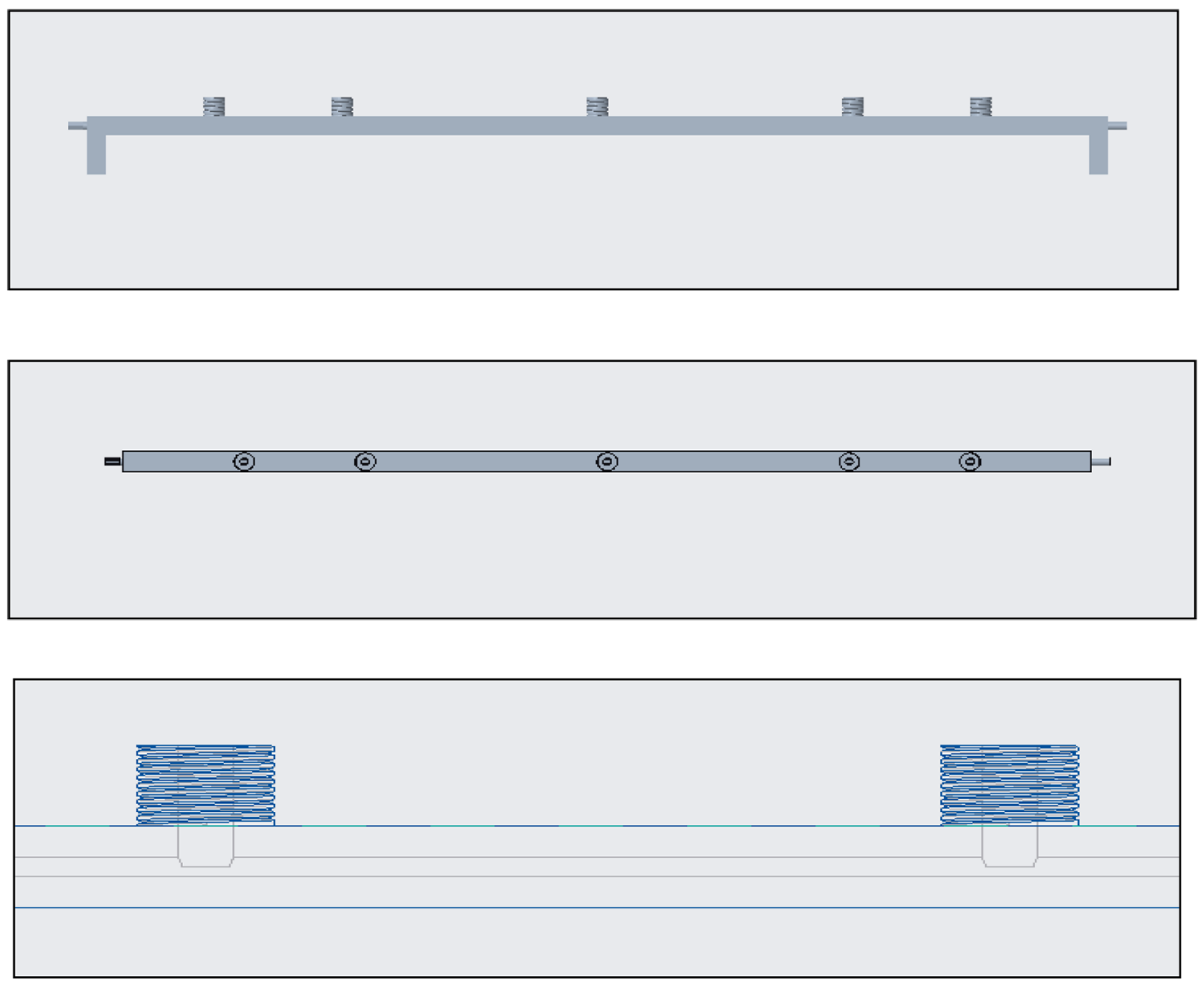

Fig. 3. Nozzle panel.

deep bag filters with the necessary efficiencies. Filter portions are equipped with latches to allow for easy removal and maintenance.

- Electrical Control Panel: The control panel enclosure for the device is made of thick gauge sheet steel with a baked phosphatized powder coat finish. According to IEC 529 requirements, the enclosure complies with IP54. For easy access and security, a hinged access door with a key-fastener is provided. The panel is factory wired to NEC430 \& 440 standards, is labeled, and tagged, and has $220 \mathrm{~V} / 240 \mathrm{~V}$ controls.

- Casing/Structure: Casing is made to be easy to handle and install at a minimal cost. Factory constructed and installed on a firm foundation, the PACV-D Air Cooled Packaged Units. The unit casing of PACV-D Packaged units is made of zinc coated galvanized steel sheets that are phosphatized and baked after an electrostatic powder coat of approximately 60 microns, according to JIS-G 3302 and ASTM A653. Water cannot penetrate the PACV-D series packaged air conditioner interior since the complete casing panels are engineered to be leak proof. Vinyl gasketing was used to seal the evaporator area.

\subsection{Designing of adiabatic precooling system components}

The designed industrial standard package unit PACV-D series 54125-D used for adiabatic precooling system was designed using Creo software which would ensure the efficient working of the package unit and the corresponding views of the package unit have been shown in Figure 7.

\subsection{Energy analysis}

To conduct energy efficiency analysis for the unit SKM PACV-D series 54125-D Packaged Air Conditioners, we need to calculate the energy consumed before implementing the adiabatic system and after implementing adiabatic system to calculate the energy savings. Table 1 shows the package unit specifications and was based on the following conditions. The capacity figures are based on an air-dry bulb temperature of $80^{\circ} \mathrm{F}\left(26.7^{\circ} \mathrm{C}\right)$ and the capacity includes gross capacity, which excludes the heat generated by the evaporator fan motor. The shaded values in the Table 1 represents condenser entering air temperatures of $120^{\circ} \mathrm{F}\left(49^{\circ} \mathrm{C}\right)$. 

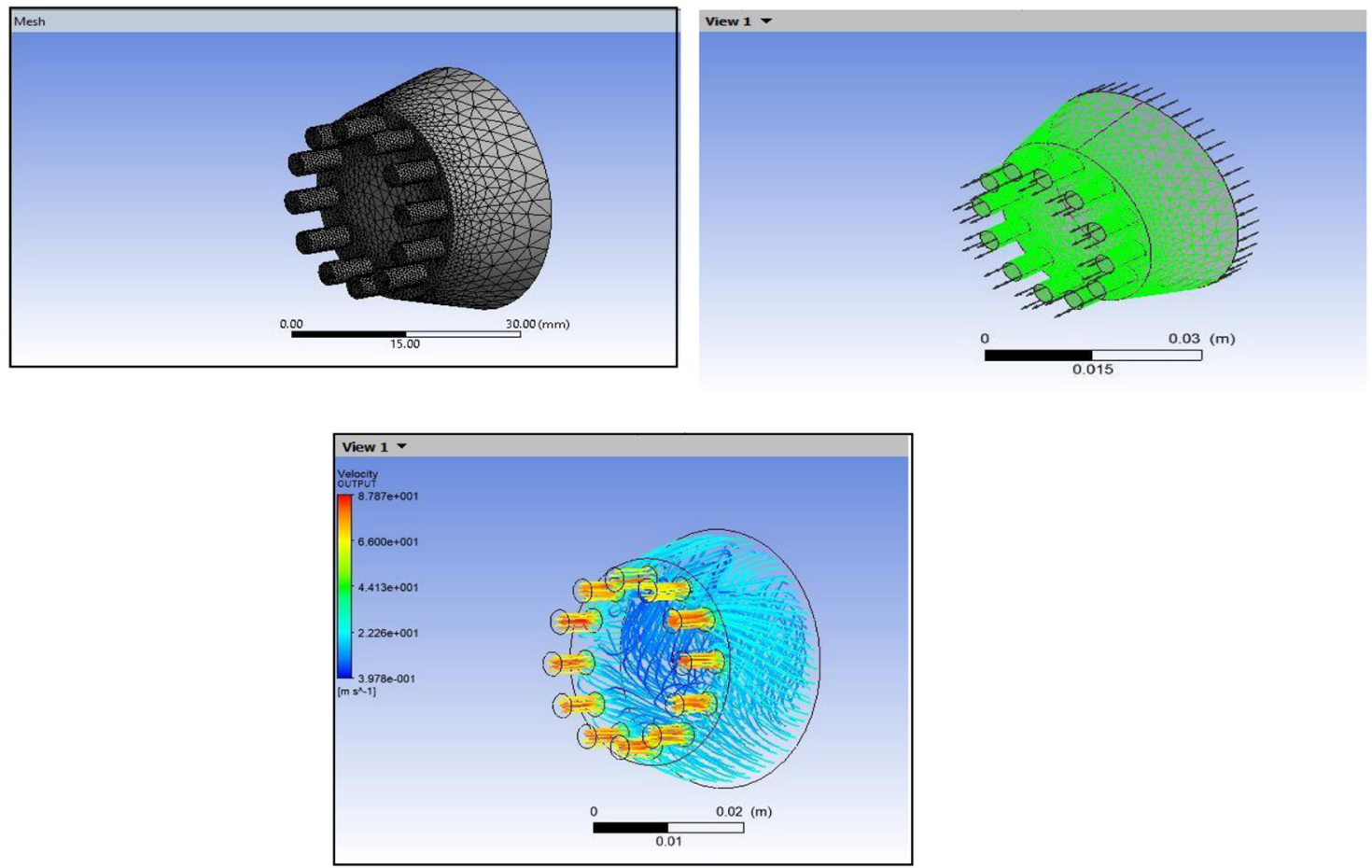

Fig. 4. Meshing, inlet and outlet boundary condition and flow analysis of nozzle.
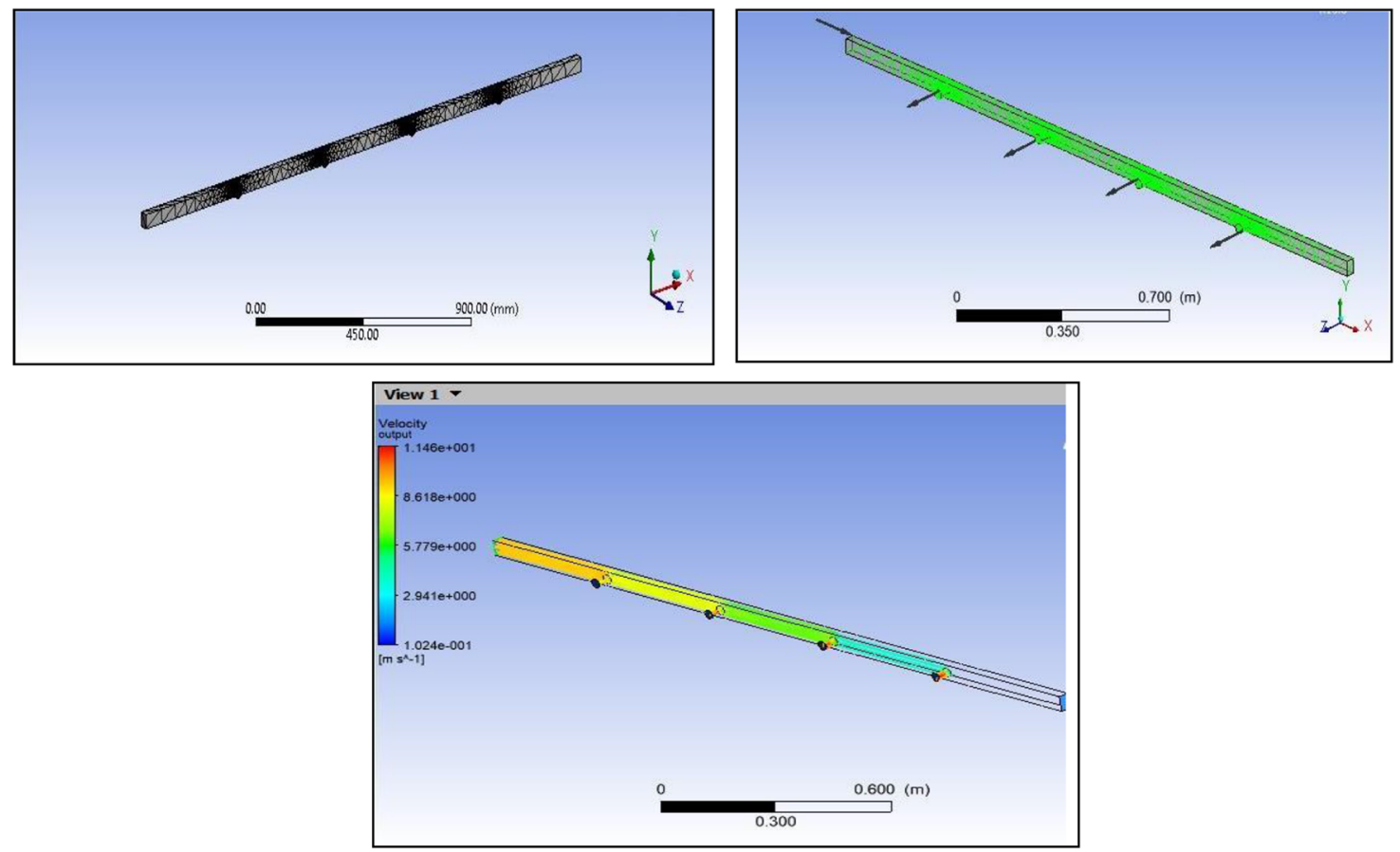

Fig. 5. Meshing, boundary conditions and analysis of nozzle panel. 

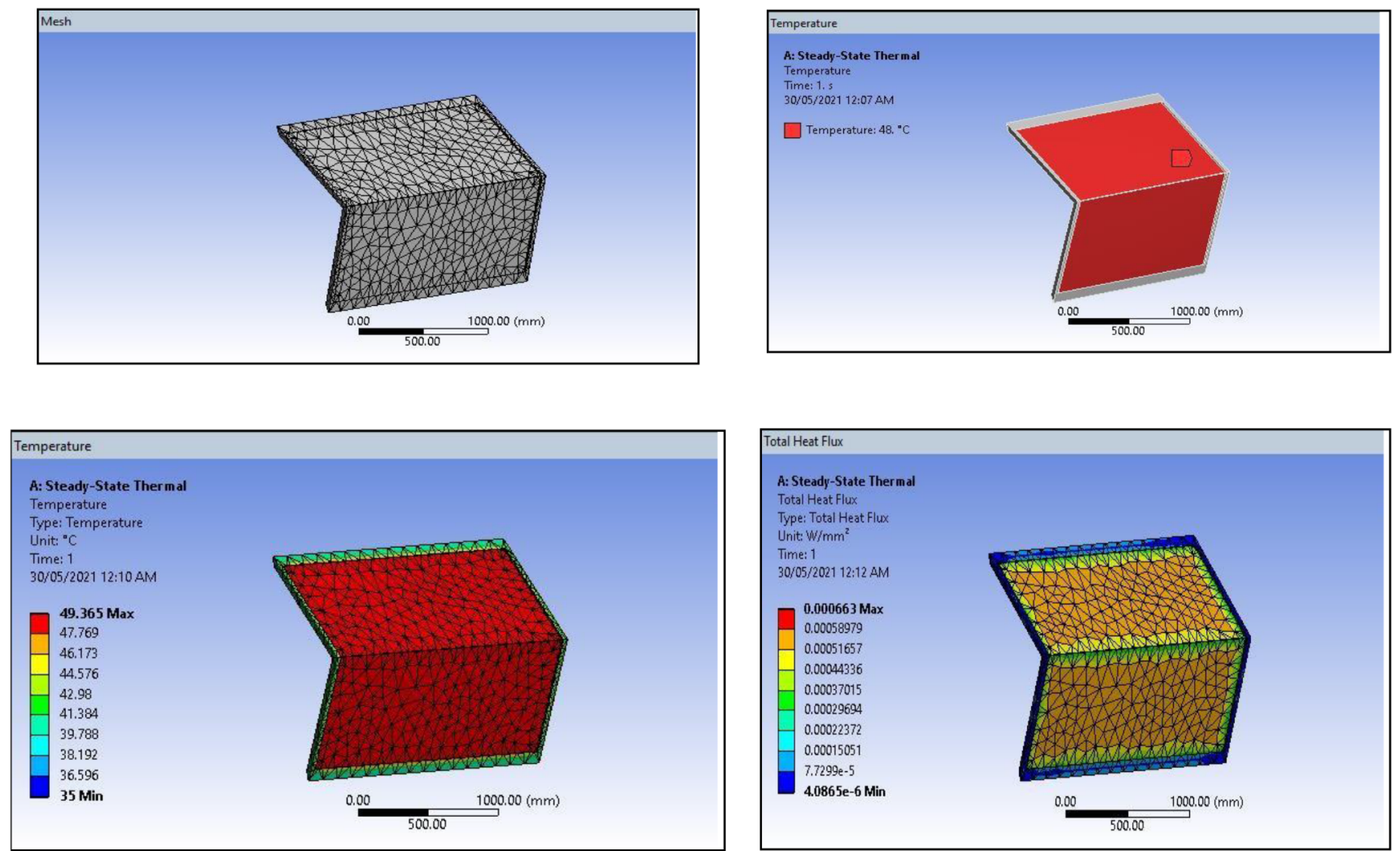

Fig. 6. Meshing of membrane panel, temperature, steady state thermal and heat flux analysis.
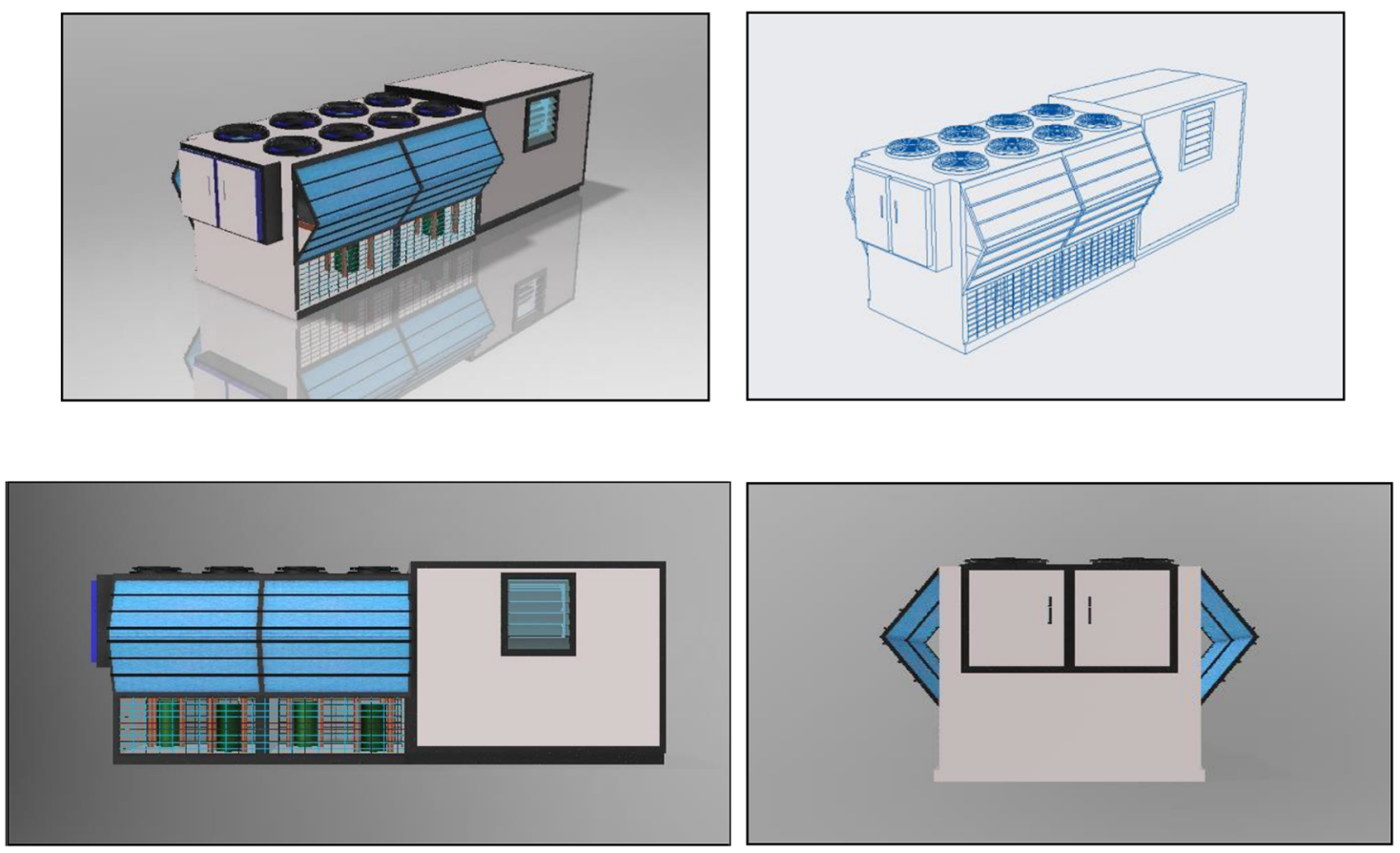

Fig. 7. Adiabatic system in package unit, wire frame modelling, left and top view. 
Table 1. Specifications from the package unit catalog.

\begin{tabular}{|c|c|c|c|c|c|c|c|c|c|c|c|c|c|c|c|c|c|c|}
\hline \multirow{4}{*}{$\begin{array}{l}\text { Model } \\
\text { PACV }\end{array}$} & \multirow{4}{*}{$\begin{array}{l}\text { AFR } \\
\mathrm{cfm} \\
\text { I/s } \\
\text { (BPF) }\end{array}$} & & & \multicolumn{15}{|c|}{ Condenser Entering Air Temperature } \\
\hline & & \multirow{2}{*}{\multicolumn{2}{|c|}{ EWB }} & \multicolumn{5}{|c|}{$95^{\circ} \mathrm{F}\left(35^{\circ} \mathrm{C}\right)$} & \multicolumn{5}{|c|}{$105^{\circ} \mathrm{F}\left(40.6^{\circ} \mathrm{C}\right)$} & \multicolumn{5}{|c|}{$115^{\circ} \mathrm{F}\left(46.1^{\circ} \mathrm{C}\right)$} \\
\hline & & & & \multicolumn{2}{|c|}{ Total Capacity } & \multicolumn{2}{|c|}{ Sensible Capacity } & \multirow{2}{*}{$\begin{array}{l}P I^{\circ} \\
\text { KW }\end{array}$} & \multicolumn{2}{|c|}{ Total Capacity } & \multicolumn{2}{|c|}{ Sensible Capacity } & \multirow{2}{*}{$\begin{array}{l}\mathrm{Pl} \\
\mathrm{kW}\end{array}$} & \multicolumn{2}{|c|}{ Total Capacity } & \multicolumn{2}{|c|}{ Sensible Capacity } & \multirow{2}{*}{$\begin{array}{l}\mathrm{Pl} \\
\mathrm{KW}\end{array}$} \\
\hline & & ${ }^{\circ} \mathrm{F}$ & ${ }^{\circ} \mathrm{C}$ & MBh & kW & MBh & kW & & MBh & kW & MBh & $\mathrm{kW}$ & & MBh & kW & MBh & kW & \\
\hline \multirow{9}{*}{54125.0} & 29750 & 62 & 16.7 & 1218.2 & 357.1 & 1046.2 & 306.6 & 121.3 & 1158 & 399.4 & 1018.9 & 298.6 & 127.8 & 1095.4 & 321.1 & 990.9 & 290.4 & 134.8 \\
\hline & 14040 & 67 & 19.4 & 1317.8 & 3062 & 874.4 & 256.3 & 127.1 & 1258.8 & 388.4 & 849.4 & 249 & 134.5 & 1193.2 & 349.7 & 823.7 & 241.4 & 142.7 \\
\hline & 0.03 & 72 & 222 & 1431.8 & 419.7 & 702.9 & 206 & 133.6 & 136.5 & 400.2 & 678.6 & 198.9 & 141.7 & 1296.4 & 30 & 653.9 & 191.7 & 150.7 \\
\hline & 40000 & 62 & 16.7 & 1225.9 & 379.8 & 1244.8 & 364.8 & 125.9 & 1226.4 & 359.4 & 1215.2 & 3562 & 1324 & 1142.5 & 334.9 & 1142.5 & 3349 & 138.6 \\
\hline & 18878 & 67 & 19.4 & 1409.6 & 413.1 & 1023.3 & 2999 & 132.3 & 1341.9 & 393.3 & 997.7 & 2924 & 140.1 & 1271.8 & 3728 & 971.3 & 284.7 & 148.8 \\
\hline & 0.04 & 72 & 222 & 1528.5 & 448 & 799.5 & 2343 & 138.8 & 14549 & 426.4 & 7742 & 226.9 & 147.4 & 1377.3 & 403.7 & 748 & 2192 & 156.9 \\
\hline & 46750 & 62 & 16.7 & 1326.9 & 3889 & 1326.9 & 3889 & 127.6 & 12429 & 364.3 & 12429 & 3043 & 133.6 & 1162 & 340.6 & 1162 & 340.6 & 140.2 \\
\hline & 2064 & 67 & 19.4 & 1452.4 & 455.7 & 1116.8 & 3273 & 134.7 & 1381.8 & 405 & 10002 & 319.5 & 142.7 & 1308.4 & 363.5 & 10,332 & $\$ 11.6$ & 151.7 \\
\hline & 0.06 & $\pi 2$ & 222 & 1573.3 & 481.1 & 858.6 & 251.8 & 1412 & 1495 & 4382 & 8328 & 244 & 149.9 & 1413.3 & 4142 & 806 & 2362 & 159.6 \\
\hline
\end{tabular}

Table 2. Efficiency parameters after incorporating adiabatic system.

\begin{tabular}{lll}
\hline COP & EER & SEER \\
\hline 3.20 & 11.1 & 11.1 \\
\hline
\end{tabular}

\subsection{Energy efficiency ratio (EER)}

Energy Efficiency Ratio (EER) stands for Energy Efficiency Ratio. Divide the BTU (British Thermal Units) rating by the wattage to get the EER rating for an air conditioner. In general, an EER of 8 or greater is considered energy efficient; however, when comparing two models, the one with the greater EER, regardless of whether it is over 8, is more energy efficient.

$$
\begin{aligned}
& \mathrm{EER}=\text { Btu's } / \text { Watts } \\
& \text { Cooling capacity }=461.1 \mathrm{~kW} \\
& 1 \text { Ton }=3.51 \mathrm{~kW} \\
& \text { Cooling capacity }=131.1 \mathrm{TR} \\
& 1 \mathrm{TR}=12000 \text { Btu } \\
& \mathrm{Btu}=131.1 \times 12000 \\
& \mathrm{EER}=1,574,400 / 141200=11.1 .
\end{aligned}
$$

\subsection{Seasonal energy efficiency ratio}

The seasonal energy efficiency ratio is frequently used to rate the efficiency of air conditioners (SEER). The cooling output during a normal cooling season is divided by the total electric energy intake during the same period to determine the SEER rating of a unit. The SEER rating of a unit indicates how energy efficient it is. The SEER is the ratio of cooling energy consumed in watt-hours to cooling energy consumed in British thermal units (BTUs). In the following section, the coefficient of performance (COP), a more universal unit-less measure of efficiency, is explained.

$$
\mathrm{SEER}=((\mathrm{BTU} / \mathrm{h}) / \mathrm{W}=1,574,400 / 141200=11.1 .
$$

\subsection{Coefficient of performance (COP)}

The Coefficient of Performance (COP) is a measurement of how efficient a heat pump or air conditioner is at transmitting heat compared to the amount of electricity it consumes.

$$
\begin{aligned}
\mathrm{COP} & =\text { Cooling capacity } / \text { power input }=461.1 / 141.2 \\
& =3.20
\end{aligned}
$$

Table 2 shows the efficiency parameters considering COP, EER and SEER after incorporating adiabatic system.

\subsection{Energy and capital consumption}

From the Table 1 considering the total capacity, sensible capacity, and power input for 45.1-degree centigrade ambient temperature before installation of adiabatic precooling system and 35-degree centigrade ambient temperature after installation of adiabatic precooling system to calculate energy efficiency analysis. This package unit can run on $25 \%$ to $100 \%$ capacity depending upon the load. In this analysis we have considered the package unit running at $100 \%$ capacity. The corresponding cooling capacity estimated hours and Energy savings in case of package units can be observed in Table 3. 
Table 3. Cooling capacity, estimated hours and expected energy savings of package unit.

\begin{tabular}{lllllll}
\hline $\begin{array}{l}\text { Cooling } \\
\text { capacity } \\
(\mathrm{Q} / \mathrm{kW})\end{array}$ & $\begin{array}{l}\text { Condenser unit to } \\
\text { be cooled } \\
\text { (Units) }\end{array}$ & $\begin{array}{l}\text { Estimated } \\
\text { hours /day } \\
(\mathrm{Hrs})\end{array}$ & $\begin{array}{l}\text { Days of } \\
\text { operation per } \\
\text { month }\end{array}$ & $\begin{array}{l}\text { Months of AC } \\
\text { operation } \\
\text { per year }\end{array}$ & $\begin{array}{l}\text { Cost of } \\
\text { electricity } \\
\text { kWh(AED })\end{array}$ & $\begin{array}{l}\text { Expected energy } \\
\text { savings } \\
(\%)\end{array}$ \\
\hline 414.2 & 4 & 15 & 30 & 8 & 0.4 & 20 \\
\hline
\end{tabular}

\subsection{Energy efficiency and capital consumption without an adiabatic system at ambient temperature of 46.1-degree centigrade}

From the Table 1, the power consumed by SKM PACV-D series 54125-D packaged air conditioners per hour at 46.1-degree centigrade is $159.6 \mathrm{~kW} / \mathrm{h}$. Therefore, energy consumed per day is equal to power consumed per hour multiplied by estimated hours to operation per day considering 15 will be equal to $2394 \mathrm{~kW} / \mathrm{h}$. The energy consumed per month is equal to power consumed per hour multiplied by estimated hours to operation per day multiplied by days of operation per month (30 days) is equal to $71820 \mathrm{~kW} / \mathrm{h}$. The energy consumed per year considering 8 months will be equal to $574200 \mathrm{~kW} / \mathrm{h}$. So, the cost of electricity per day ( $0.45 \mathrm{AED}$ per $\mathrm{kWh}$ ) will be equal to 1077.3 AED and similarly the cost of electricity per month and year will be 32319 AED and 258390 AED.

\subsection{Energy efficiency and capital consumption with an adiabatic system at ambient temperature of 35-degree centigrade}

From the Table 1, the power consumed by SKM PACV-D series 54125-D packaged air conditioners per hour at 46.1-degree centigrade is $141.2 \mathrm{~kW} / \mathrm{h}$. Therefore, energy consumed per day is equal to power consumed per hour multiplied by estimated hours to operation per day considering 15 will be equal to $2118 \mathrm{~kW} / \mathrm{h}$. The energy consumed per month is equal to power consumed per hour multiplied by estimated hours to operation per day multiplied by days of operation per month (30 days) is equal to $63540 \mathrm{~kW} / \mathrm{h}$. The energy consumed per year considering 8 months will be equal to $508320 \mathrm{~kW} / \mathrm{h}$. So, the cost of electricity per day ( $0.45 \mathrm{AED}$ per $\mathrm{kWh}$ ) will be equal to $953.1 \mathrm{AED}$ and similarly the cost of electricity per month and year will be 28593 AED and 228744 AED.

From the above discussion of energy efficiency and capital consumption with and without an adiabatic process. It is observed that the energy consumed, and the cost of electricity is less in case of adiabatic system as compared to without an adiabatic system. The calculations show the relative advantage for the consumer who invested in adiabatic cooling system in package unit.

\subsection{Energy and capital savings}

From Table 1 it is observed that the total cooling capacity of package unit at 46.1 degree centigrade is $414.2 \mathrm{~kW} / \mathrm{h}$ and total cooling capacity at 35 degrees Celsius is $461.1 \mathrm{~kW} / \mathrm{h}$.
Therefore, energy conserved per hour in terms of total cooling capacity is $46.9 \mathrm{~kW} / \mathrm{h}$. Similarly, power consumed per hour at 46.1 degree centigrade and power consumed per hour at 35 degrees centigrade is 159.6 and $141.2 \mathrm{~kW} / \mathrm{h}$. Therefore, energy conserved per hour in terms of electric current consumed is equal to $18.4 \mathrm{~kW} / \mathrm{h}$ considering the operation hours for one day as 15 hours. The energy saved pee day will be equal to energy conserved per hour multiplied by operation hours for one day in full load is equal to $276 \mathrm{~kW} / \mathrm{h}$. Therefore, energy saved per month and year will be equal to 8280 and $66240 \mathrm{~kW} / \mathrm{h}$. The capital savings per day is equal to energy saved per day multiplied by cost of electricity per $\mathrm{kW} / \mathrm{h}$ is equal to $124.2 \mathrm{AED}$. Similarly, the capital savings per day for month and year will be 3726 AED and 29808 AED.

\subsection{Return on investment analysis}

The ratio of net income to investment is known as return on investment (ROI). A high return on investment (ROI) indicates that the investment's benefits outweigh its cost. ROI is a performance metric that is used to assess an investment's efficiency or to compare the efficiencies of several distinct investments.

The cost of electricity per $\mathrm{kWh}$ is equal to $0.45 \mathrm{AED}$ and the cost per month is equal to energy saved per month multiplied by cost of electricity per $\mathrm{kWh}$ which is equal to 3726 AED. The cost for a season ( 8 months) is equal to 29808 AED.

The cost of water per liter is equal to $0.046 \mathrm{AED}$ and the water consumed in one month in imperial gallon is equal to $36835 \mathrm{IG}$ and the water consumed in one season in imperial gallon is 392680 IG. So, the water consumption per month and one season is equal to 1740 AED and 13932 AED.

To calculate the efficiency improvements in terms of COP (Coefficient of Performance) before and after implementing the adiabatic cooling system. The ambient temperature (in ${ }^{\circ} \mathrm{F} /{ }^{\circ} \mathrm{C}$ ), cooling capacity (in $\mathrm{kW}$ ), power (in $\mathrm{kW}$ ) and COP for this the test results and the efficiency improvement for air-cooled package unit illustrated in the following Table 4 . Note the power input mentioned is for compressor only.

\section{Conclusions}

An industrial standard package unit (PACV-D series 54125-D) was considered for the study in this research paper by considering the adiabatic system. Creo was used 
to perform flow and thermal analysis on the designed components such as nozzle, membrane, and the nozzle panel. Further, the entire package system was studied with respect to energy saving and efficiency by considering adiabatic system based upon the set parameters. This study was elaborated by the rate of return of investment and the energy efficiency analysis was conducted to improve the adaptability rate and remain as an option to general consumer. The following conclusions can be drawn from this research article.

- From the energy efficiency ratio, it can be concluded that the energy efficiency is more than 11.1 which clearly states that the system is more energy efficient and return on investment is high.

- From the coefficient of performance point of view this machine consumes less electricity.

- The Expected energy saving is $20 \%$ if the cost of electricity is considered as 0.4 AED.

- From this research article it can be concluded that energy efficiency increases if adiabatic cooling system is included in the package unit.

\section{References}

1. B. Porumb, P. Unguresan, L.F. Tutunaru, A. Serban, M. Balan, A review of indirect evaporative cooling technology, Energy Proc. 85, 461-471 (2016)

2. A.L. Basediya, D.V.K. Samuel, V. Beera, Evaporative cooling system for storage of fruits and vegetables - a review, J. Food Sci. Technol. 50, 429-442 (2013)

3. S. Jafari, J.F. Dunne, M. Langari, Z. Yang, J.-P. Pirault, C.A. Long, J.T. Jose, A review of evaporative cooling system concepts for engine thermal management in motor vehicles, Proc. Inst. Mech. Eng. D J. Automob. Eng. 231, 1126-1143 (2016)

4. S. Sibanda, T.S. Workneh, Performance evaluation of an indirect air cooling system combined with evaporative cooling, Heliyon 6, 1-8 (2020)

5. M. Ramzan, M.S. Kamran, M.W. Saleem, H. Ali, M. Ibrahim, M. Zeinelabdeen, Energy efficiency improvement of the split air conditioner through condensate assisted evaporative cooling, Arab. J. Sci. Eng. 46, 7719-7727 (2021)

6. H. Yang, L. Rong, X. Liu, L.S. Liu, M. Fan, N. Pei, Experimental research on spray evaporative cooling system applied to air-cooled chiller condenser, Energy Rep. 6, 906913 (2020)

7. M. Yan, S. He, M. Gao, M. Xu, J. Miao, X. Huang, K.H. An, Comparative study on the cooling performance of evaporative cooling systems using seawater and freshwater, Int. J. Refrig. 121, 23-32 (2021)

8. S. Abaranji, K. Panchabikesan, V. Ramalingam, Experimental investigation of a direct evaporative cooling system for yearround thermal management with solar-assisted dryer, Rec. Adv. Sustain. Solar Energy Technol. 2020, 1-24 (2020)

9. A.P. Sawant, N. Agrawal, P. Nanda, Performance assessment of an evaporative cooling-assisted window air conditioner, Int. J. Low-Carbon Technol. 7, 128-136 (2012)

10. J.K. Jain, D.A. Hindoliya, Energy saving potential of indirect evaporative cooler under Indian climates, Int. J. Low-Carbon Technol. 11, 193-198 (2016) 
11. H.M.U. Raza, M. Sultan, M. Bahrami, A.A. Khan, Experimental investigation of evaporative cooling systems for agricultural storage and livestock air conditioning in pakistan, Buil. Simul. 14, 617-631 (2021)

12. S. Noor, H. Ashraf, M. Sultan, Z.M. Khan, Evaporative cooling options for building air-conditioning: A comprehensive study for climatic conditions of Multan (Pakistan), Energies 13, 3061 (2020)

13. K. Rajesh, E. Jacob, CFD simulation for evaluation of optimum heat transfer rate in a heat exchanger of an internal combustion engine, Int. J. Simul. Multidiscipl. Des. Optim. 11, 1-9 (2020)
14. R. EL Maani, S. Elouardi, B. Radi, A. EI Hami, Multiobjective aerodynamic shape optimization of NACA0012 airfoil based mesh morphing, Int. J. Simul. Multidiscipl. Des. Optim. 11, 1-10 (2020)

15. K. Jairam, F.M. Musthafa, K. Annanth, V.M. Renganathan, Computational investigations on port injected DEE in a biogas inducted HCCI engine, Int. J. Simul. Multidiscipl. Des. Optim. 12, 1-9 (2020)

16. SKM packaged Air conditioning unit PACV-D-R-134a, Air conditioning equipment, SKM Air conditioning LLC, Infinity Tower Dubai, 1-48, 2021.

Cite this article as: Sachin Sunil Mothiravally, Sachidananda Hassan Krishanmurthy, Design of an adiabatic air conditioning package system, Int. J. Simul. Multidisci. Des. Optim. 13, 8 (2022) 